\title{
Fungal Diversity in Tomato Rhizosphere Soil under Conventional and Desert Farming Systems
}

\author{
Elham A. Kazerooni, Sajeewa S. N. Maharachchikumbura, Velazhahan Rethinasamy, \\ Hamed Al-Mahrouqi and Abdullah M. Al-Sadi*
}

Department of Crop Sciences, College of Agricultural and Marine Sciences, Sultan Qaboos University, Muscat, Oman

\section{OPEN ACCESS}

Edited by:

Magdalena Frac

Institute of Agrophysics (PAN), Poland

Reviewed by:

Ravindra Nath Kharwar,

Banaras Hindu University, India

Somayeh Dolatabadi,

Westerdijk Fungal Biodiversity

Institute, Netherlands

*Correspondence:

Abdullah M. Al-Sadi

alsadi@squ.edu.om

Specialty section:

This article was submitted to

Fungi and Their Interactions,

a section of the journal

Frontiers in Microbiology

Received: 04 June 2017

Accepted: 20 July 2017

Published: 02 August 2017

Citation:

Kazerooni EA,

Maharachchikumbura SSN,

Rethinasamy V, Al-Mahrouqi H and Al-Sadi AM (2017) Fungal Diversity in Tomato Rhizosphere Soil under Conventional and Desert Farming Systems. Front. Microbiol. 8:1462. doi: 10.3389/fmicb.2017.01462
This study examined fungal diversity and composition in conventional (CM) and desert farming (DE) systems in Oman. Fungal diversity in the rhizosphere of tomato was assessed using 454-pyrosequencing and culture-based techniques. Both techniques produced variable results in terms of fungal diversity, with $25 \%$ of the fungal classes shared between the two techniques. In addition, pyrosequencing recovered more taxa compared to direct plating. These findings could be attributed to the ability of pyrosequencing to recover taxa that cannot grow or are slow growing on culture media. Both techniques showed that fungal diversity in the conventional farm was comparable to that in the desert farm. However, the composition of fungal classes and taxa in the two farming systems were different. Pyrosequencing revealed that Microsporidetes and Dothideomycetes are the two most common fungal classes in $\mathrm{CM}$ and DE, respectively. However, the culture-based technique revealed that Eurotiomycetes was the most abundant class in both farming systems and some classes, such as Microsporidetes, were not detected by the culture-based technique. Although some plant pathogens (e.g., Pythium or Fusarium) were detected in the rhizosphere of tomato, the majority of fungal species in the rhizosphere of tomato were saprophytes. Our study shows that the cultivation system may have an impact on fungal diversity. The factors which affected fungal diversity in both farms are discussed.

Keywords: farming system, fungal community, pathogen, saprophytes, desert fungi

\section{INTRODUCTION}

Soil is a precious and complex natural resource that represents a huge reservoir of biodiversity with several billion prokaryotic and eukaryotic microorganisms. These microbes significantly share biomass and ecosystem functions in both natural and managed agricultural soils (Sidorenko et al., 1978). Microbial diversity is directly or indirectly affected by cultivation techniques, management practices, crop rotation, soil tillage, animal grazing, plant species and climatic changes (AcostaMartínez et al., 2014; Chen et al., 2017; Gangireddygari et al., 2017; Liu et al., 2017; Yao et al., 2017). Variations in soil temperature, precipitation and soil $\mathrm{pH}$ also influence soil fungal diversity. Fungi are the dominant eukaryotes among soil microbial communities where they play crucial and key roles in terrestrial ecosystems (Abed et al., 2013; Peay et al., 2013; Acosta-Martínez et al., 2014).

Oman is situated at an arid region in the eastern part of the Arabian Peninsula and in summer, the temperature can rise up to $50^{\circ} \mathrm{C}$. Most farms in Oman use traditional methods to promote biodiversity by cultivating several crops in the same field. The majority of farms in the northern 
part of the country grow date palms, while rest occupies citrus, vegetable crops such as tomatoes and cucumbers and other crops (Kazeeroni and Al-Sadi, 2016). Tomato is the major vegetable crop produced in Oman with the total production of over 70,000 tons in 2014 (FAO, 2015). Most tomato production in Oman is in commercial farms in the main agricultural area, the Batinah region. However, some of the farms that are located in desert areas also produce crops including tomatoes.

Microbial abundance, diversity and activity largely have implications on sustainable productivity of agricultural land and production systems. Information on the microbial communities associated with rhizospheres and their complex interrelationship is essential in the selection of sustainable crop rotations and management practices (Lenc et al., 2015; Chen et al., 2017). Direct culture of microorganisms and molecular methods are widely used to analyze soil microbes (Al-Sadi et al., 2015; Thomson et al., 2015; Kazeeroni and Al-Sadi, 2016). With the advent of next generation sequencing technologies, 454 pyrosequencing is used nowadays for assessing fungal diversity because of its high sensitivity (Esmaeili Taheri et al., 2015; Kazeeroni and Al-Sadi, 2016).

Although several studies addressed tomatoes, the information about the occurrence and the organization of fungal organisms in the tomato rhizosphere is currently limited. Furthermore, studies on fungal diversity in desert farming systems remain rare. Considering the different ways that can change the farming systems underlying soils and soil microbes, it is essential to understand the fungal diversity and their functions in soils under different managements. In this study, we examined soil fungal composition and diversity using pyrosequencing and culturebased techniques in two different tomato-farming systems: commercial vs. desert. Our main objective was to study how the changes of soil fungal communities vary with the different farming techniques. Knowledge in these areas will help predict how fungal communities vary under varying cultivation systems.

\section{MATERIALS AND METHODS}

\section{Collection of Samples}

Soil samples were collected from conventional and desert farms in Barka and Thumrait, Oman during June 2014 and the information on the details of the locations and weather conditions of the soils samples are mentioned in Table 1. Each soil was collected along random directions from three different lots of each tomato plant, approximately about $1 \mathrm{~kg}$ from each sample, taken from 10 to $12 \mathrm{~cm}$ depth near the active growing roots. The soil samples were kept in sterile plastic bags and brought to the laboratory. All samples were thoroughly homogenized before stored at $10^{\circ} \mathrm{C}$.

\section{Soil Analysis}

Soil samples were air-dried and sieved. Soil texture, $\mathrm{pH}$ and electrical conductivity (EC) were determined using standard methods (Gee and Bauder, 1986; Zhang et al., 2005). Determination of potassium $(\mathrm{K})$ and phosphorus $(\mathrm{P})$ were done using a flame photometric method (Sheerwood 450 flame photometer) and Inductively Coupled Plasma (Perkin Elmer, United States), respectively. Organic and inorganic carbon levels were determined using Total Organic Carbon analyzer (TOC-V, Shimadzu, Japan). Total nitrogen $(\mathrm{N})$ was estimated by Kjeldahl distillation method using Kjeltec Analyser (FOSS TECATOR, Sweden). Differences among soils were examined using SAS (SAS Institute Inc., United States).

\section{Direct Plating}

This method was performed for isolating fungi from soil samples. Soil samples (0.1-0.15 g) were plated onto rose Bengalamended 2.5\% potato dextrose agar (Oxoid, England) plates using three replicates for each sample. Incubation was at $25^{\circ} \mathrm{C}$ for 3-7 days. Fungal colonies present on the incubation plates were subcultured for identification.

\section{Identification of Fungi}

Fungal isolates were identified based on morphological characteristics under light microscope and sequences data. Fungal isolates were grown on PDA for 3-7 days. Then fungal isolates were preliminarily assigned to different genera based on the size and shape of spores and mycelia.

To confirm the identity of fungi, DNA was extracted from freeze dried mycelium using the protocol of Lee and Taylor (1990). The ITS region was amplified using the primer pair ITS1 and ITS4 (White et al., 1990) as explained by Al-Sadi et al. (2011). Additional loci ( $\beta$-tubulin, Calmodulin, RNA polymerase II second largest subunit, Translation elongation factor 1-alpha) were used to identify the species of Aspergillus, Cladosporium, Fusarium and Penicillium using the primers and conditions detailed in literature (Carbone and Kohn, 1999; Samson et al., 2014). Purification and sequencing of PCR products were carried out at Macrogen, Korea. Sequences were aligned and improved using MEGA v.6 (Tamura et al., 2013). A maximum likelihood analysis was performed by using raxmlGUI v.1.3 (Silvestro and Michalak, 2012) for the isolates that belong to the kingdom fungi using the ITS region. The optimal ML tree search was conducted with 1000 separate runs, using the default algorithm. Bootstrap 50\% majority-rule consensus trees were generated and the final tree was selected among suboptimal trees from each run by comparing likelihood scores under the GTRGAMMA substitution model. ITS sequences generated from the analysis were deposited in GenBank (Table 2).

\section{Pyrosequencing Analyses}

DNA was extracted from 3 to 5 replicates from each soil sample according to the protocol of Volossiouk et al. (1995). A twostep process was used for the amplification of samples. Firstly, the forward (i5 and ITS1F) and reverse (i7 and ITS2aR) primers were constructed as described previously (White et al., 1990; Gardes and Bruns, 1993; Kazeeroni and Al-Sadi, 2016; Al-Balushi et al., 2017). The reaction mixtures and conditions for the first and the second PCRs were as per Al-Balushi et al. (2017). Checking of sequences was done using RDP ver 9 (Cole et al., 2009). Analysis and taxonomic classification was done using a distributed BLASTn.NET algorithm (Dowd et al., 2005) based on a $97 \%$ cut off. Fungi were classified based on trimmed taxa. 
TABLE 1 | Physicochemical properties of soil samples.

\begin{tabular}{|c|c|c|c|c|c|c|c|c|}
\hline Sample name & Soil texture & $\mathrm{pH}$ & $\mathrm{EC}(\mathrm{mS})$ & $\%$ TIC & \%тOC & $\% \mathbf{N}$ & $P\left(\mathrm{mg} \mathrm{kg}^{-1}\right)$ & $\mathrm{K}\left(\mathrm{mg} \mathrm{kg}^{-1}\right)$ \\
\hline $\mathrm{CM}$ & Sandy & $8.0 \mathrm{a}$ & $1.28 b$ & $5.27 \mathrm{a}$ & $3.464 \mathrm{a}$ & $0.056 \mathrm{a}$ & $5.076 \mathrm{a}$ & $61.876 \mathrm{a}$ \\
\hline DE & Loamy sand & $7.8 \mathrm{a}$ & $7.72 \mathrm{a}$ & $4.13 \mathrm{a}$ & $2.768 \mathrm{a}$ & $0.020 \mathrm{~b}$ & 3.272 b & $45.639 \mathrm{~b}$ \\
\hline
\end{tabular}

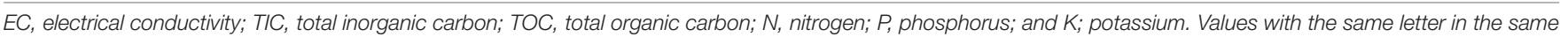
column are not significantly different from each other at $P<0.05$ (Tukey's Studentized Range test, SAS).

TABLE 2 | ITS GenBank accession numbers of fungal isolates detected in this study.

\begin{tabular}{lc}
\hline Fungal isolates & Accession number \\
\hline Aspergillus pachycristatus & $\mathrm{KY} 814690$ \\
Aspergillus quadrilineatus & $\mathrm{K} Y 814680$ \\
Aspergillus quadrilineatus & $\mathrm{KY} 814684$ \\
Aspergillus quadrilineatus & $\mathrm{KY} 814689$ \\
Aspergillus rugulosus & $\mathrm{KY} 814676$ \\
Aspergillus rugulosus & $\mathrm{KY} 814688$ \\
Aspergillus rugulosus & $\mathrm{KY} 814687$ \\
Cephaliophora sp. & $\mathrm{KY} 814682$ \\
Chaetomium sp. & $\mathrm{KY} 814677$ \\
Cladosporium tenuissimum & $\mathrm{KY} 814674$ \\
Fusarium chlamydosporum & $\mathrm{KY} 814673$ \\
Fusarium chlamydosporum & $\mathrm{KY} 814685$ \\
Fusarium nygamai & $\mathrm{KY} 814686$ \\
Fusarium solani & $\mathrm{KY} 814675$ \\
Fusarium solani & $\mathrm{KY} 814679$ \\
Fusarium solani & $\mathrm{KY} 814691$ \\
Mortierella sp. & $\mathrm{KY} 814683$ \\
Penicillium corylophilum & $\mathrm{KY} 814681$ \\
Pythium aphanidermatum & $\mathrm{KY} 814678$ \\
\hline & \\
\hline
\end{tabular}

The relative abundance for individual taxa was then determined after checking the percentage of sequences assigned to each fungal phylogenetic level.

\section{RESULTS}

\section{Soil Analysis}

Soils differed in their properties (Table 1). The CM soil was sandy, while the soil from DE was loamy sandy. The $\mathrm{pH}$ was found to be alkaline in DE (7.8) and CM (8), while EC was significantly higher in DE (7.72) compared to CM (1.27) $(P<0.05$; Table 1). The total inorganic carbon (TIC) and total organic carbon (TOC) concentrations were not significantly different between $\mathrm{CM}$ and DE $(P>0.05)$. The available $\mathrm{N}, \mathrm{P}$, and $\mathrm{K}$ concentration were significantly higher in the $\mathrm{CM}$ farming system compared to $\mathrm{DE}$ $(P<0.05$; Table 1$)$.

\section{Phylogenetic Analysis}

The ITS alignment was used to represent the fungal species recovered from direct plating technique. The alignment comprised 68 strains (including the outgroup taxon Allomyces reticulatus and 18 isolates recovered in this study), and the manually adjusted dataset comprised 959 characters including gaps. A best scoring RAxML tree resulted with the value of Likelihood: -11745.862498 (Supplementary Figure S1). Based on the phylogenetic tree, 18 isolates from the present study belonged to Ascomycota phylum (classes Dothideomycetes, Eurotiomycetes, Pezizomycetes and Sordariomycetes), while the subdivision Mucoromycotina belonged to the phylum Zygomycota. Fungal classes were separated from each other with a very high bootstrap support (94-100\%). Some of the isolates could not be matched with appropriate reference strains in GenBank, suggesting that some isolates could be new species or the sequence of their corresponding species are not available in GenBank.

\section{Evaluation of Fungal Diversity by Culture-Based Technique}

Ascomycota was the most abundant phylum, present in both farming systems and Oomycota and Zygomycota were the other constituents. The phylum Oomycota was present only in CM while Zygomycota was present only in DM. In Ascomycota, soil samples from both farms presented a high relative abundance of Eurotiomycetes at class level (42.85\% in CM, 40\% in DE). This was followed by Sordariomycetes $(42.85 \%)$ and Dothideomycetes (7.1\%) in CM while Sordariomycetes and Pezizomycetes were found in the same level of abundance in the DE farming system (20\%). Dothideomycetes and Oomycetes were unique classes in CM while Zygomycetes and Pezizomycetes were unique classes in DE (Figure 1). Totally eight genera were recovered from both farming systems and these were dominated by Aspergillus (Figure 2). A total of 12 fungal species were isolated from both farming systems. The most common species across two farming systems was Aspergillus quadrilineatus. Cephaliophora sp., Mortierella sp. and Penicillium corylophilum were only present in DE while Chaetomium sp., Cladosporium tenuissimum, Aspergillus pachycristatus, A. rugulosus, F. nygamai, F. solani and Pythium aphanidermatum were unique in CM. The Shannon values were 2.0 for soil from CM compared to 1.6 from DE (Table 3).

\section{Evaluation of Fungal Diversity by Pyrosequencing Technique}

Using a $97.0 \%$ similarity barcoding threshold, pyrosequencing showed that the majority of fungal taxa in CM was in the Microsporidia (60.26\%), followed by Ascomycota (28.5\%), Chytridiomycota (3.51\%), Basidiomycota (0.77\%) and Zygomycota (0.01\%). All the Microsporidia belonged to a single class Microsporidetes. Ascomycota was distributed over classes Leotiomycetes (4.5\%), Dothideomycetes (3\%) and 


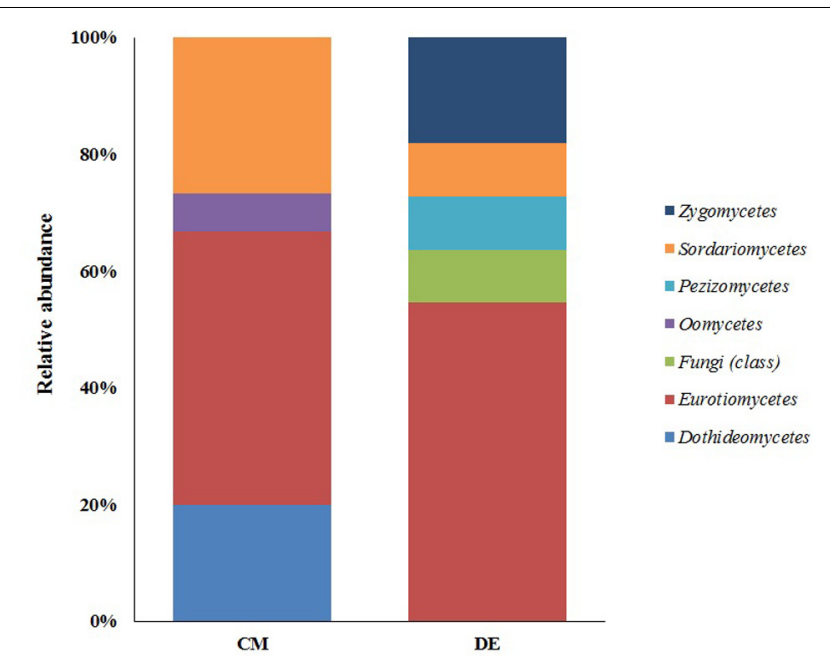

FIGURE 1 | Class-level relative abundance of fungal communities in commercial farming (CM) and desert farming (DE) systems using culture-based technique.

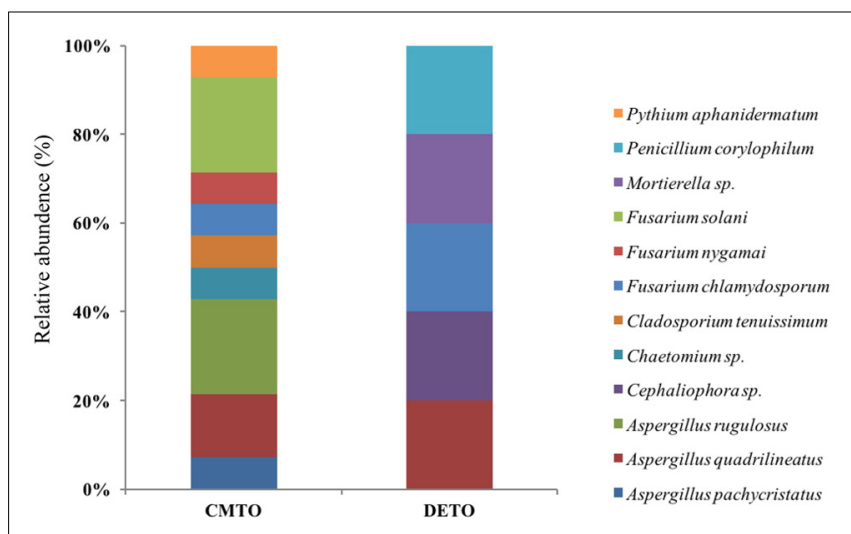

FIGURE 2 | Species-level relative abundance of fungal communities in commercial farming (CM) and desert farming (DE) systems using culture-based technique.

TABLE 3 | Shannon-Wiener index of commercial farm (CM) and desert farm (DE) as determined by direct plating technique.

\begin{tabular}{lllllll}
\hline & \multicolumn{3}{c}{ Direct plating } & & \multicolumn{2}{c}{ Pyrosequencing } \\
\cline { 2 - 3 } \cline { 5 - 6 } & CM & DE & & CM & DE \\
\hline No. of phyla & 2 & 2 & & 5 & 3 \\
No. of classes & 4 & 4 & & 8 & 9 \\
No. of families & 5 & 4 & & 9 & 11 \\
No. of genera & 5 & 5 & & 10 & 11 \\
No. of species & 9 & 5 & & 15 & 11 \\
Shannon Wiener index & 2.0 & 1.6 & & 1.4 & 1.9
\end{tabular}

Sordariomycetes (1.5\%). In DE over 95\% of all OTUs belonged to the phylum Ascomycota, which was distributed in four classes; Dothideomycetes (38.07\%), Eurotiomycetes (24.07\%), Leotiomycetes (5.77\%) and Sordariomycetes (4.04\%). Another

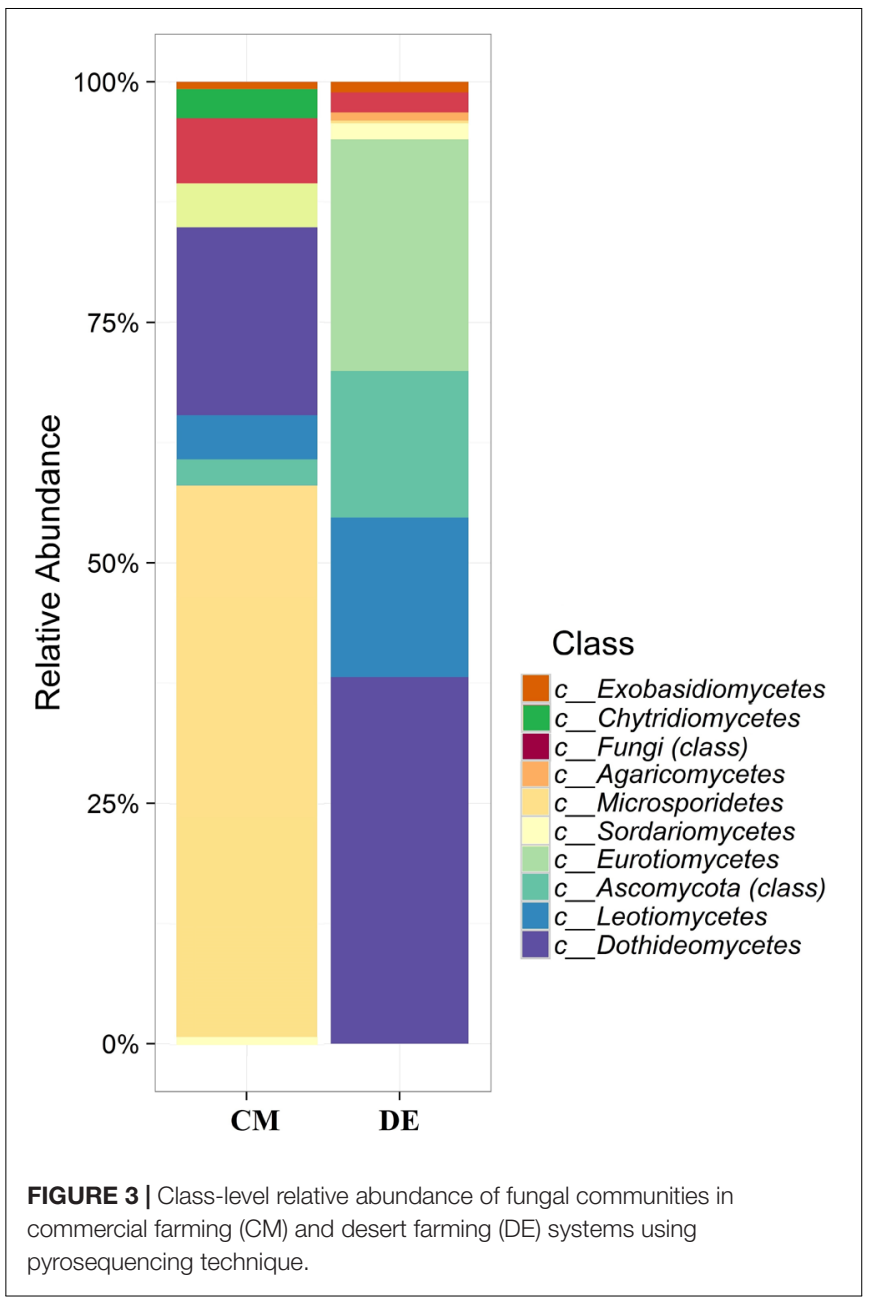

$23.73 \%$ could not be assigned to any classes and kept as Ascomycota incertae sedis. Zygomycota and Chytridiomycota were absent in the DE and Microsporidia contribution is in lesser amount $(0.3 \%)$. The distribution of classes based on pyrosequencing is illustrated in Figure 3. The pyrosequencing approach yielded a total of 15 species in CM, with a Shannon value of 1.4 (Figure 4 and Table 3). Systenostrema alba was the most dominant, comprising $60 \%$ of the total species in CM, followed by Rhizina undulata (17.56\%) Mortierella sp. (4.17\%) and Oidium aloysiae (4.04\%). Pyrosequencing detected 11 fungal species in DE, with a Shannon value of 1.9 (Table 3). Cladosporium sp. (27\%) and Emericella nidulans were the most abundant taxa, followed by Trichocladium asperum (12.8\%), Phoma gardeniae (11\%) and Symbiotaphrina kochii (10.94\%).

\section{Direct Plating vs. Pyrosequencing}

Direct plating and pyrosequencing methods were used in this study for estimating fungal abundance and diversity in two different farming systems of tomato. The water molds (Oomycetes) were not picked up by pyrosequencing and only detected by the culture-based method. On the other hand, Basidiomycota, Chytridiomycota and unicellular parasites 


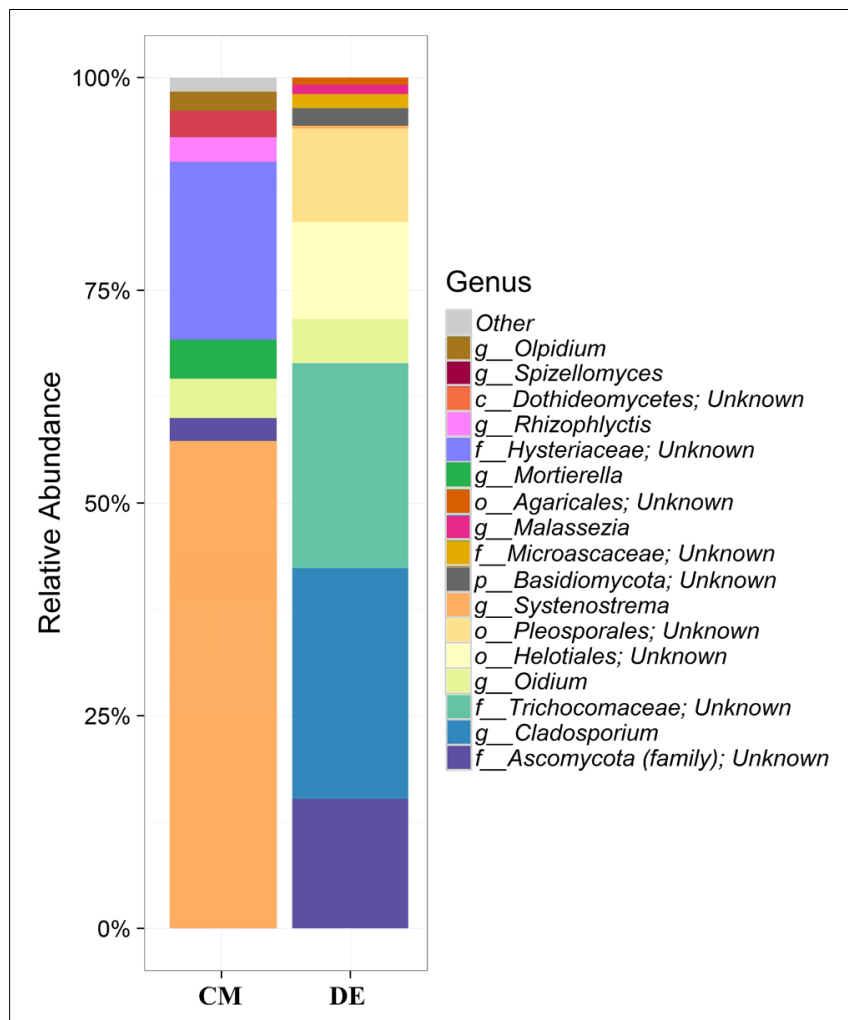

FIGURE 4 | Generic-level relative abundance of fungal communities in commercial farming (CM) and desert farming (DE) systems using pyrosequencing technique.

Microsporidias were unable to be recovered using direct plating. Pyrosequencing detected more species compared to direct plating technique (Table 3 ).

\section{DISCUSSION}

Several studies using molecular techniques and cultivation-based methods have described the fungal communities present in different farming systems (Al-Sadi et al., 2015; Van Geel et al., 2015; Kazeeroni and Al-Sadi, 2016). These studies have shown that fungal communities present in each system vary with the soil physiochemical properties and the cropping systems (Huang et al., 2015; Thomson et al., 2015). Our results demonstrate that CM and DE soil are highly diverse in soil microbiota. In general, the fungal diversity in the CM farming system was high compared to the DE system. The presence of relatively high percentage of TOC and TIC in both farming systems may be favorable for the growth of most fungi. In addition, N, P and $\mathrm{K}$ levels are relatively high in CM soil and this is probably because of the addition of a certain amount of organic and chemical fertilizers to the soil. Thus, the application of fertilizers by growers could have contributed to creating differences in the available minerals in soils between the two farming systems and soil types (Grüter et al., 2017; Wang et al., 2017). Grantina et al. (2011) reported positive impact of the available potassium in soil on the total number of cultivable filamentous fungi (CFF) and on the fungal diversity. In another investigation, a negative impact of phosphorus was observed on species richness of fungi in soil (Huang et al., 2005). As suggested by Gyaneshwar et al. (2002), this could be due to variations in the number of phosphate solubilizing microorganisms in soil.

Ascomycota is the largest and widespread phylum of fungi and is abundant in soil and composts (Abed et al., 2013; De Gannes et al., 2013; Kazeeroni and Al-Sadi, 2016). They are considered important decomposers and causal agents of several soil-borne diseases. In the present study based on the culturebased technique, Ascomycota was dominant in both farming systems. Eurotiomycetes was identified as the dominant class in both CM and DE, mainly because it contains two of the most common fungal genera viz., Penicillium and Aspergillus in most of the ecosystems (Godinho et al., 2015; Yee et al., 2016). Many saprophytic fungi were detected in DE; whereas plant pathogenic fungi viz., Cladosporium sp., Fusarium spp. and Pythium sp. were detected in CM soil. In the present study, Fusarium that causes wilt disease in tomato was detected in CM soil samples. The prevalence of Fusarium in CM soil might be due to the potential ability of chlamydospores of Fusarium to survive in the soil for many years under harsh environmental conditions. Chellemi et al. (2012) demonstrated that repeated tomato cultivation increased the incidence of Fusarium wilt caused by F. oxysporum f. sp. lycopersici by $20 \%$ or more.

The mycoparasite, Chaetomium sp. was detected in the CE soil. However, other fungal biocontrol agents like Trichoderma spp. and Gliocladium virens were not detected in both the farming systems. The existence of these organisms in soil is crucial for suppression of damping off and Fusarial wilt diseases of tomato (Blaya et al., 2013; Guzmán-Valle et al., 2014). Hence, the soil health in both the farming systems has to be improved by incorporation of organic amendments and application of biopesticides. Some of the fungal isolates could not be identified to the species level, possibly because they are new species or they need more genes to be sequenced. Future studies may address the identity of these isolates.

Pyrosequencing revealed that $95 \%$ of the taxa in DE soil belonged to the Ascomycota, whereas $60 \%$ of the taxa present in CM soil belonged to the phylum Microsporidia (a group of sporeforming unicellular parasites) and the genus Systenostrema. This is in agreement with our previous findings that Microsporidia are one of the dominant phyla in soil of farming systems in Oman (Kazeeroni and Al-Sadi, 2016). Microsporidia are obligate, sporeforming, fungi-related, intracellular parasites that infect many vertebrates and invertebrates. Several species of microsporidia have been described as biocontrol agents and pathogens of several beneficial insects (Bjornson and Oi, 2014). For example, Nosema pyrausta is effective in controlling European corn borer (Ostrinia nubilalis) (Lewis et al., 2009). A formulation of Paranosema locustae is commercially available for biological control of rangeland grasshoppers (Bjornson and Oi, 2014). Several studies reported that Microsporidia are natural intracellular parasites of the nematodes including Caenorhabditis (Kaya et al., 1988; Troemel et al., 2008; Zhang et al., 2016). The Microsporidia, Nematocida parisii was reported as a natural intracellular 
pathogen of Caenorhabditis elegans (Troemel et al., 2008). Zhang et al. (2016) described six new species in the Nematocida genus that are capable of infecting Caenorhabditis elegans.

In general, fungal species diversity was higher with the pyrosequencing than the culture-based method. These dissimilarities are to be expected and are not surprising since many of the fungi are not cultivable. Some studies showed that approximately $1 \%$ of the total microbes could be detected by culture-based methods (Sugiyama et al., 2010). On the contrary, some fungi can easily be cultured even they are present in small quantities. In addition, the high temperature in the Omani desert, which sometimes exceeds $50^{\circ} \mathrm{C}$ in summer, could have affected fungal diversity in soil by killing or suppressing several fungal species that are heat sensitive (Abed et al., 2013; Classen et al., 2015; Costa et al., 2015). This in turn could have affected the number of fungal species recovered from soil by culturedependent methods. Also the absence of Chytridiomycota and Basidiomycota in culture-based method could have been because they either need specific media or their presence was limited as evidenced by pyrosequencing analysis (only $3.51 \%$ and less than $0.77 \%$ of the total soil population, respectively) (Gleason et al., 2007; Yee et al., 2016). Therefore, the detection of the precise diversity of fungi in a habitat using culture-based techniques is still challengeable. Pyrosequencing recovered more species that were not revealed by the culture-based method, implying that this approach will speed up the detection of very rare fungal species (Huang et al., 2015; Liu et al., 2017). However, pyrosequencing still has some limitations in describing fungal diversity. Future studies should investigate if using other media in addition to PDA and also other genes for pyrosequencing could help recover more fungal species and reduce the existing gap between pyrosequencing and culture based techniques.

\section{CONCLUSION}

This study provided evidence that farming systems strongly influence the composition of soil fungal communities. It is surprising to note that a few soil fungi that were detected by direct

\section{REFERENCES}

Abed, R. M. M., Al-Sadi, A. M., Al-Shehi, M., Al-Hinai, S., and Robinson, M. D. (2013). Diversity of free-living and lichenized fungal communities in biological soil crusts of the Sultanate of Oman and their role in improving soil properties. Soil Biol. Biochem. 57, 695-705. doi: 10.1016/j.soilbio.2012.07.023

Acosta-Martínez, V., Cotton, J., Gardner, T., Moore-Kucera, J., Zak, J., Wester, D., et al. (2014). Predominant bacterial and fungal assemblages in agricultural soils during a record drought/heat wave and linkages to enzyme activities of biogeochemical cycling. Appl. Soil Ecol. 84, 69-82. doi: 10.1016/j.apsoil.2014. 06.005

Al-Balushi, I., Bani-Uraba, M., Guizani, N., Al-Khusaibi, M., and Al-Sadi, A. M. (2017). Illumina MiSeq sequencing analysis of fungal diversity in stored dates. BMC Microbiol. 17:72. doi: 10.1186/s12866-017-0985-7

Al-Sadi, A. M., Al-Mazroui, S. S., and Phillips, A. J. L. (2015). Evaluation of culturebased techniques and 454 pyrosequencing for the analysis of fungal diversity in potting media and organic fertilizers. J. Appl. Microbiol. 119, 500-509. doi: $10.1111 /$ jam. 12854 culturing method could not be detected by pyrosequencing. More research is required by using different soil DNA extraction procedures. Culturing fungi by using multiple nutrient media might result in the isolation of additional fungi from soil. Viability of fungal communities in soil needs to be considered when assessing their diversity in a farming system. One of the major drawbacks in PCR-based methods is their inability to discriminate between nucleic acids from viable and dead cells. The DNA extracted from dead cells can also serve as a template in PCR amplification. To overcome such issues, viability PCR using propidium monoazide (PMA) that differentiate nucleic acids from live and dead cells (Cangelosi and Meschke, 2014) has to be tested.

\section{AUTHOR CONTRIBUTIONS}

AA-S, EK, SM, and HA-M planned the experiment. EK and HA-M conducted the experiment, AA-S, EK, SM, and VR analyzed data, EK, AA-S, SM, VR, and HA-M wrote the manuscript. All authors approved the manuscript.

\section{ACKNOWLEDGMENTS}

Financial support from Sultan Qaboos University (IG/AGR/CROP/16/03) and Oman Animal and Plant Genetic Resources Center (EG/AGR/CROP/16/01) is highly appreciated.

\section{SUPPLEMENTARY MATERIAL}

The Supplementary Material for this article can be found online at: http://journal.frontiersin.org/article/10.3389/fmicb. 2017.01462/full\#supplementary-material

FIGURE S1 | Phylogenetic analysis of fungi recovered from direct plating based on ITS data set. The tree is rooted with Allomyces reticulatus (Blastocladiomycota). RAxML bootstrap values higher than $50 \%$ are given above or below the nodes. The isolates from present study are in bold.

Al-Sadi, A. M., Al-Said, F. A., Al-Jabri, A. H., Al-Mahmooli, I. H., Al-Hinai, A. H., and de Cock, A. W. A. M. (2011). Occurrence and characterization of fungi and oomycetes transmitted via potting mixtures and organic manures. Crop Protect. 30, 38-44. doi: 10.1016/j.cropro.2010.09.015

Bjornson, S., and Oi, D. (2014). "Microsporidia biological control agents and pathogens of beneficial insects," in Microsporidia: Pathogens of Opportunity, 1st Edn, eds L. M. Weiss and J. J. Becnel (Chichester: John Wiley \& Sons, Inc.). doi: 10.1002/9781118395264.ch25

Blaya, J., López-Mondéjar, R., Lloret, E., Pascual, J. A., and Ros, M. (2013). Changes induced by Trichoderma harzianum in suppressive compost controlling Fusarium wilt. Pestic. Biochem. Physiol. 107, 112-119. doi: 10.1016/j.pestbp. 2013.06.001

Cangelosi, G. A., and Meschke, J. S. (2014). Dead or alive: molecular assessment of microbial viability. Appl. Environ. Microbiol. 80, 5884-5891. doi: 10.1128/AEM. 01763-14

Carbone, I., and Kohn, L. M. (1999). A method for designing primer sets for speciation studies in filamentous ascomycetes. Mycologia 91, 553-556. doi: $10.2307 / 3761358$ 
Chellemi, D. O., Wu, T., Graham, J. H., and Church, G. (2012). Biological impact of divergent land management practices on tomato crop health. Phytopathology 102, 597-608. doi: 10.1094/PHYTO-08-11-0219

Chen, Y. L., Xu, T. L., Veresoglou, S. D., Hu, H. W., Hao, Z. P., Hu, Y. J., et al. (2017). Plant diversity represents the prevalent determinant of soil fungal community structure across temperate grasslands in northern China. Soil Biol. Biochem. 110, 12-21. doi: 10.1016/j.soilbio.2017.02.015

Classen, A. T., Sundqvist, M. K., Henning, J. A., Newman, G. S., Moore, J. A. M., Cregger, M. A., et al. (2015). Direct and indirect effects of climate change on soil microbial and soil microbial-plant interactions: What lies ahead? Ecosphere 6:130. doi: 10.1890/es15-00217.1

Cole, J. R., Wang, Q., Cardenas, E., Fish, J., Chai, B., Farris, R. J., et al. (2009). The Ribosomal Database Project: improved alignments and new tools for rRNA analysis. Nucleic Acids Res. 37, D141-D145. doi: 10.1093/nar/gkn879

Costa, O. Y. A., Souto, B. M., Tupinambá, D. D., Bergmann, J. C., Kyaw, C. M., Kruger, R. H., et al. (2015). Microbial diversity in sugarcane ethanol production in a Brazilian distillery using a culture-independent method. J. Ind. Microbiol. Biotechnol. 42, 73-84. doi: 10.1007/s10295-014-1533-1

De Gannes, V., Eudoxie, G., and Hickey, W. J. (2013). Insights into fungal communities in composts revealed by 454-pyrosequencing: implications for human health and safety. Front. Microbiol. 4:164. doi: 10.3389/fmicb.2013. 00164

Dowd, S. E., Zaragoza, J., Rodriguez, J. R., Oliver, M. J., and Payton, P. R. (2005). Windows.NET network distributed basic local alignment search toolkit (W.ND-BLAST). BMC Bioinformatics 6:93. doi: 10.1186/1471-2105-6-93

Esmaeili Taheri, A., Hamel, C., and Gan, Y. (2015). Pyrosequencing reveals the impact of foliar fungicide application to chickpea on root fungal communities of durum wheat in subsequent year. Fungal Ecol. 15, 73-81. doi: 10.1016/j.funeco. 2015.03.005

FAO (2015). FAOSTAT. Available at: http://faostat3.fao.org/browse/rankings/ countries_by_commodity/E [accessed October 5, 2016].

Gangireddygari, V. S. R., Kalva, P. K., Ntushelo, K., Bangeppagari, M., Djami Tchatchou, A., and Bontha, R. R. (2017). Influence of environmental factors on biodegradation of quinalphos by Bacillus thuringiensis. Environ. Sci. Europe 29, 1-10. doi: 10.1186/s12302-017-0109-x

Gardes, M., and Bruns, T. (1993). ITS primers with enhanced specificity for basidiomycetes-application to the identification of mycorrhizae and rusts. Mol. Ecol. 2, 113-118. doi: 10.1111/j.1365-294X.1993.tb00005.x

Gee, G. W., and Bauder, J. W. (1986). "Particle size analysis," in Methods of Soil Analysis, Part-I. Physical and Mineralogical Methods, ed. A. Klute (Madison, WI: American Society of Agronomy), 383-411.

Gleason, F. H., Letcher, P. M., and McGee, P. A. (2007). Some aerobic Blastocladiomycota and Chytridiomycota can survive but cannot grow under anaerobic conditions. Australas. Mycol. 26, 57-64.

Godinho, V. M., Gonçalves, V. N., Santiago, I. F., Figueredo, H. M., Vitoreli, G. A., Schaefer, C. E. G. R., et al. (2015). Diversity and bioprospection of fungal community present in oligotrophic soil of continental Antarctica. Extremophiles 19, 585-596. doi: 10.1007/s00792-015-0741-6

Grantina, L., Kenigsvalde, K., Eze, D., Petrina, Z., Skrabule, I., Rostoks, N., et al. (2011). Impact of six-year-long organic cropping on soil microorganisms and crop disease suppressiveness. Zemdirbyste Agric. 98, 399-408.

Grüter, R., Costerousse, B., Bertoni, A., Mayer, J., Thonar, C., Frossard, E., et al. (2017). Green manure and long-term fertilization effects on soil zinc and cadmium availability and uptake by wheat (Triticum aestivum L.) at different growth stages. Sci. Total Environ. 59, 1330-1343. doi: 10.1016/j.scitotenv.2017. 05.070

Guzmán-Valle, P., Bravo-Luna, L., Montes-Belmont, R., Guigón-López, C., and Sepúlveda-Jiménez, G. (2014). Induction of resistance to Sclerotium rolfsii in different varieties of onion by inoculation with Trichoderma asperellum. Eur. J. Plant Pathol. 138, 223-229. doi: 10.1007/s10658-013-0336-y

Gyaneshwar, P., Naresh Kumar, G., Parekh, L. J., and Poole, P. S. (2002). Role of soil microorganisms in improving P nutrition of plants. Plant Soil 245, 83-93. doi: 10.1023/A:1020663916259

Huang, P. M., Wang, M. K., and Chiu, C. Y. (2005). Soil mineral-organic mattermicrobe interactions: impacts on biogeochemical processes and biodiversity in soils. Pedobiologia 49, 609-635. doi: 10.1016/j.pedobi.2005.06.006

Huang, X., Liu, L., Wen, T., Zhu, R., Zhang, J., and Cai, Z. (2015). Illumina MiSeq investigations on the changes of microbial community in the
Fusarium oxysporum f.sp. cubense infected soil during and after reductive soil disinfestation. Microbiol. Res. 181, 33-42. doi: 10.1016/j.micres.2015.08.004

Kaya, H. K., Kopenhoffer, M., and Johnson, M. (1988). Natural enemies of entomopathogenic nematodes. Japan J. Nematol. 28, 13-21. doi: 10.3725/ jjn1993.28.supplement_13

Kazeeroni, E. A., and Al-Sadi, A. M. (2016). 454-pyrosequencing reveals variable fungal diversity across farming systems. Front. Plant Sci. 7:314. doi: 10.3389/ fpls.2016.00314

Lee, S. B., and Taylor, J. W. (1990). "Isolation of DNA from fungal mycelia and single spores," in PCR Protocols: A Guide to Methods and Applications, eds M. A. Innis, D. H. Gelfand, J. J. Sninsky, and T. J. White (New York, NY: Academic Press), 282-287.

Lenc, L., Kwaśna, H., Sadowski, C., and Grabowski, A. (2015). Microbiota in wheat roots, rhizosphere and soil in crops grown in organic and other production systems. J. Phytopathol. 163, 245-263. doi: 10.1111/jph.12313

Lewis, L. C., Bruck, D. J., Prasifka, J. R., and Raun, E. S. (2009). Nosema pyrausta: its biology, history, and potential role in a landscape of transgenic insecticidal crops. Biol. Control 48, 223-231. doi: 10.1016/j.biocontrol.2008.10.009

Liu, L., Liu, Y., Hui, R., and Xie, M. (2017). Recovery of microbial community structure of biological soil crusts in successional stages of Shapotou desert revegetation, northwest China. Soil Biol. Biochem. 107, 125-128. doi: 10.1016/j. soilbio.2016.12.030

Peay, K. G., Baraloto, C., and Fine, P. V. A. (2013). Strong coupling of plant and fungal community structure across western Amazonian rainforests. ISME J. 7, 1852-1861. doi: 10.1038/ismej.2013.66

Samson, R. A., Visagie, C. M., Houbraken, J., Hong, S.-B., Hubka, V., Klaasen, C. H. W., et al. (2014). Phylogeny, identification and nomenclature of the genus Aspergillus. Stud. Mycol. 78, 141-173. doi: 10.1016/j.simyco.2014.07.004

Sidorenko, O. D., Aristarkhova, V. I., and Chernikov, V. A. (1978). Changes in the composition and properties of humic acids brought about by the action of microorganisms of the genus Nocardia. Biol. Bull. Acad. Sci. USSR 5, $150-155$.

Silvestro, D., and Michalak, I. (2012). RaxmlGUI: a graphical front-end for RAxML. Organ. Divers. Evol. 12, 335-337. doi: 10.1007/s13127-011-0056-0

Sugiyama, A., Vivanco, J. M., Jayanty, S. S., and Manter, D. K. (2010). Pyrosequencing assessment of soil microbial communities in organic and conventional potato farms. Plant Dis. 94, 1329-1335. doi: 10.1094/pdis-02-100090

Tamura, K., Stecher, G., Peterson, D., Filipski, A., and Kumar, S. (2013). MEGA6: molecular evolutionary genetics analysis version 6.0. Mol. Biol. Evol. 30, 2725-2729. doi: 10.1093/molbev/mst197

Thomson, B. C., Tisserant, E., Plassart, P., Uroz, S., Griffiths, R. I., Hannula, S. E., et al. (2015). Soil conditions and land use intensification effects on soil microbial communities across a range of European field sites. Soil Biol. Biochem. 88, 403-413. doi: 10.1016/j.soilbio.2015.06.012

Troemel, E. R., Felix, M. A., Whiteman, N. K., Barriere, A., and Ausubel, F. M. (2008). Microsporidia are natural intracellular parasites of the nematode C. elegans. PLoS Biol. 6:e309. doi: 10.1371/journal.pbio.0060309

Van Geel, M., Ceustermans, A., Van Hemelrijck, W., Lievens, B., and Honnay, O. (2015). Decrease in diversity and changes in community composition of arbuscular mycorrhizal fungi in roots of apple trees with increasing orchard management intensity across a regional scale. Mol. Ecol. 24, 941-952. doi: $10.1111 / \mathrm{mec} .13079$

Volossiouk, T., Robb, E. J., and Nazar, R. N. (1995). Direct DNA extraction for PCR-mediated assays of soil organisms. Appl. Environ. Microbiol. 61, 3972-3976.

Wang, C., Zheng, M., Song, W., Wen, S., Wang, B., Zhu, C., et al. (2017). Impact of 25 years of inorganic fertilization on diazotrophic abundance and community structure in an acidic soil in southern China. Soil Biol. Biochem. 113, 240-249. doi: 10.1016/j.soilbio.2017.06.019

White, T. J., Bruns, T., Lee, S., and Taylor, J. (1990). "Amplification and direct sequencing of fungal ribosomal RNA genes for phylogenetics," in PCR Protocols: A Guide to Methods and Applications, eds M. A. Innis, D. H. Gelfand, J. J. Sninsky, and T. J. White (New York, NY: Academic Press), 315-322.

Yao, Q., Liu, J., Yu, Z., Li, Y., Jin, J., Liu, X., et al. (2017). Three years of biochar amendment alters soil physiochemical properties and fungal community composition in a black soil of northeast China. Soil Biol. Biochem. 110, 56-67. doi: 10.1016/j.soilbio.2017.03.005 
Yee, T. L., Tajuddin, R., Mohamed Nor, N. M. I., Mohd, M. H., and Zakaria, L. (2016). Filamentous ascomycete and basidiomycete fungi from beach sand. Rendiconti Lincei 27, 603-607. doi: 10.1007/s12210-016-0535-5

Zhang, G., Sachse, M., Prevost, M. C., Luallen, R. J., Troemel, E. R., and Félix, M. A. (2016). A large collection of novel nematode-infecting microsporidia and their diverse interactions with Caenorhabditis elegans and other related nematodes. PLoS Pathog. 12:e1006093. doi: 10.1371/journal.ppat. 1006093

Zhang, H., Schroder, L. L., Pittman, J. J., Wang, J. J., and Payton, M. E. (2005). Soil salinity using saturated paste and 1;1 soil and water extracts. Soil Sci. Soc. Am. J. 69, 1146-1151. doi: 10.2136/sssaj2004.0267
Conflict of Interest Statement: The authors declare that the research was conducted in the absence of any commercial or financial relationships that could be construed as a potential conflict of interest.

Copyright (c) 2017 Kazerooni, Maharachchikumbura, Rethinasamy, Al-Mahrouqi and Al-Sadi. This is an open-access article distributed under the terms of the Creative Commons Attribution License (CC BY). The use, distribution or reproduction in other forums is permitted, provided the original author(s) or licensor are credited and that the original publication in this journal is cited, in accordance with accepted academic practice. No use, distribution or reproduction is permitted which does not comply with these terms. 